\title{
New software
}

\section{Alias Limited release I-View}

Alias Limited, market leader for piping isometric software, today announced the availability of I-View, a 3D pipe visualization tool. I-View is capable of handling single or multiple pipes from any 3D plant design system supporting ISOGEN. Even piping files from different systems can be viewed as a single model. This new module now provides I-Sketch users with the ability to view pipes in true scale and to clash-check the piping systems visually.

The I-View model can be rotated to any angle, or the user can select a default view from a drop-down list. Individual pipe attributes are displayed by simply select- ing a pipe; information, such as the specification, pipe length and bore, will be shown in the information panel. I-View has been developed to use the familiar Windows interface and will be available as a plug-in to Internet Explorer to enable collaborative work processes via an Internet or Intranet network.

I-View is of great benefit to all companies involved in the production of piping isometrics.

For more information about I-View please visit the Alias web site www.alias.ltd.uk, or telephone or e-mail the Commercial Manager, Andy Osborne, on Tel: + 44(0) 1928 579311, e-mail: andy.osborne@alias.ltd.uk 


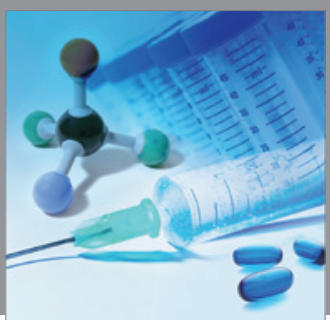

International Journal of

Medicinal Chemistry

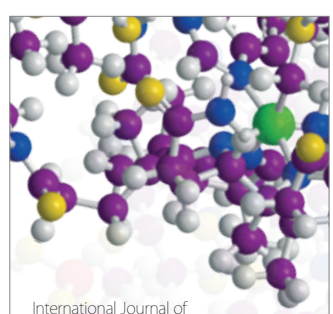

Carbohydrate Chemistry

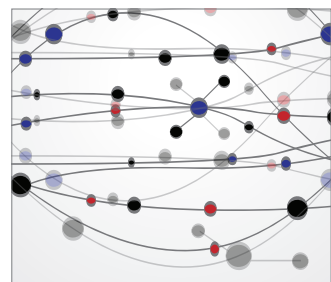

The Scientific World Journal
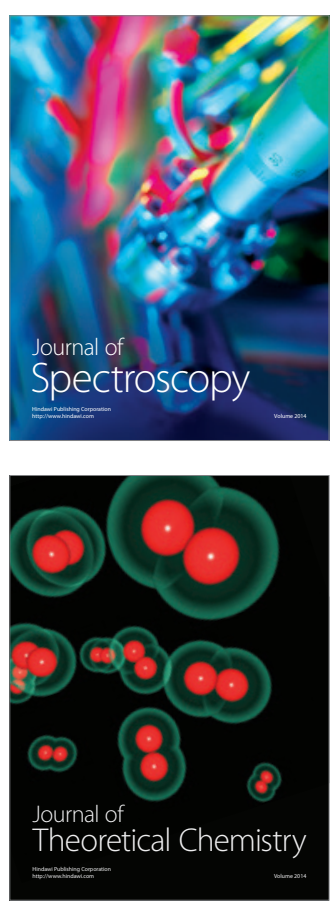
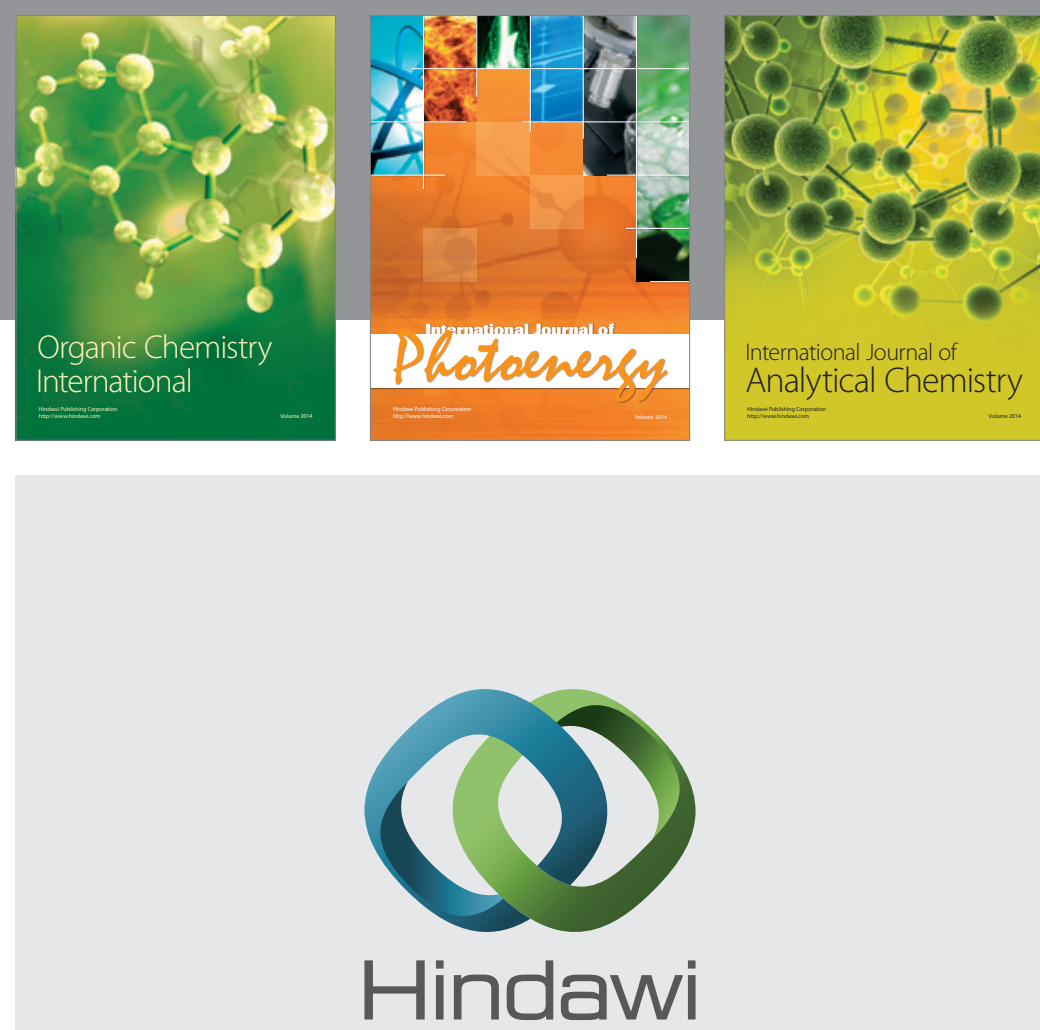

Submit your manuscripts at

http://www.hindawi.com
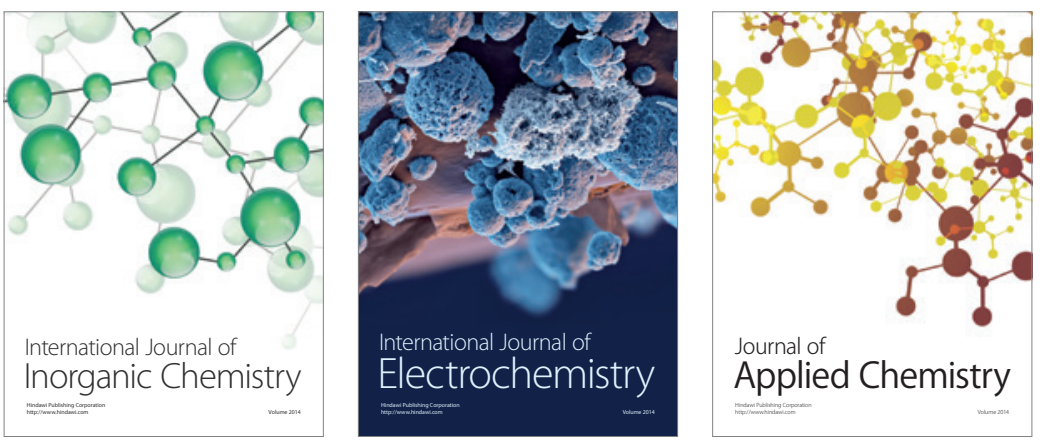

Journal of

Applied Chemistry
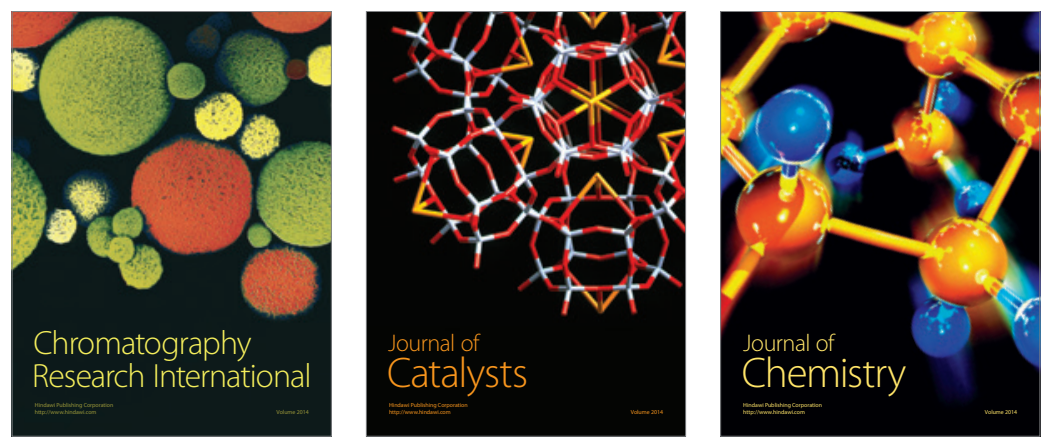
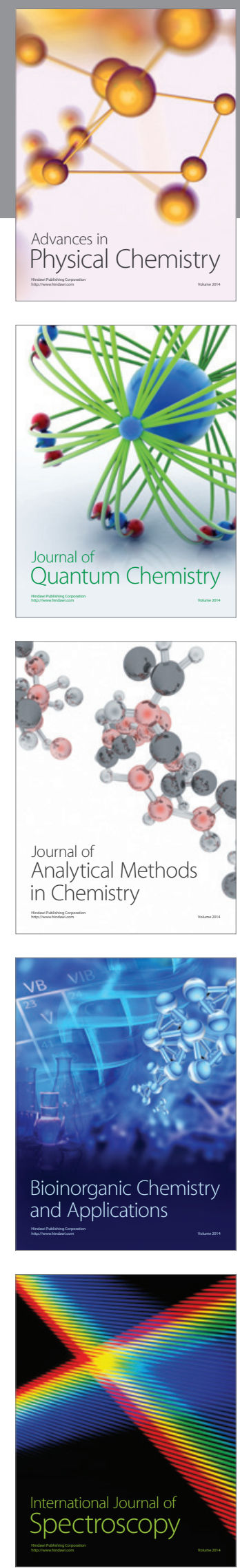